\title{
Dynamic Price Optimization for the Future of E-Commerce
}

\author{
Anusha.B ${ }^{1}$, Sangeetha.H.S ${ }^{2}$, Riyanka.R ${ }^{3}$, Sushmitha.N ${ }^{4}$, Chitra. ${ }^{5}$ \\ UG Students, Dept. of Information Science and Engineering,NIE Institute of Technology, Mysuru, India ${ }^{1,2,3,4}$ \\ Associate Professor, Dept. of Information Science and Engineering, NIE Institute of Technology, Mysuru, India ${ }^{5}$
}

\begin{abstract}
Every organisation faces a problem of setting the prices of products. The main aim of marketing strategy of an organisation is to attain marketing objectives and satisfy the targeted market. The marketing decisions affect the prices of products to a great extent. The topic of dynamic price optimization for the future of e-commerce has received a considerable amount of attention in recent years, from different scientific communities. This paper provide a brief introduction to the historical origins of quantitative research on pricing and demand estimation, point to different subfields in the area of dynamic pricing, and provide an in-depth overview of the available literature on dynamic pricing and learning. Our focus is on the operations research and management science literature, but we also discuss relevant contributions from marketing, economics, econometrics, and computer science. The topic of dynamic pricing and learning has received a considerable amount of attention in recent years, from different scientific communities. We survey these literature streams: we provide a brief introduction to the historical origins of quantitative research on pricing and Demand estimation, point to different subfields in the area of dynamic pricing, and provide an in-depth overview of the available literature on dynamic pricing and learning. Our focus is on the operations research and management science literature, but we also discuss relevant Contributions from marketing, economics, econometrics, and computer science. We discuss Relations with methodologically related research areas, and identify directions for future research.
\end{abstract}

Keywords: Dynamic Pricing, Demand Estimation; Learning, Optimization, Neural Network.

\section{INTRODUCTION}

In today's sophisticated world's competitive online market, buyers take the aid of shopbots in determining which seller to select for purchasing any product. A traditional shopbot is an online comparison service that filters products information based on different dimensions, such as price, product quality, seller's reputation etc. According to Kephart and Greenlawald [1], shopbots are internet agents that search information regarding price, quality of goods and other attributes along with services by searching different vendors. Shopbots, by providing valuable information, assist buyers in making purchase decision. The buyers in the online economy take the aid of shopbots to minimize their expenditure. Along with the existence of multiple competitive sellers, the appearance of shopbots turned the task of setting a dynamic selling price for products by a seller into a challenging one. Similar to shopbots, pricebots entered the market to aid sellers in the online economy in setting a selling price for products. Sellers make use of pricebots to maximize their profits. In dynamic pricing products prices always respond to the fluctuation of the market and hence the prices keep on changing with the tick of a clock. Every seller wants to set the selling price of their products so that their revenue is increased.

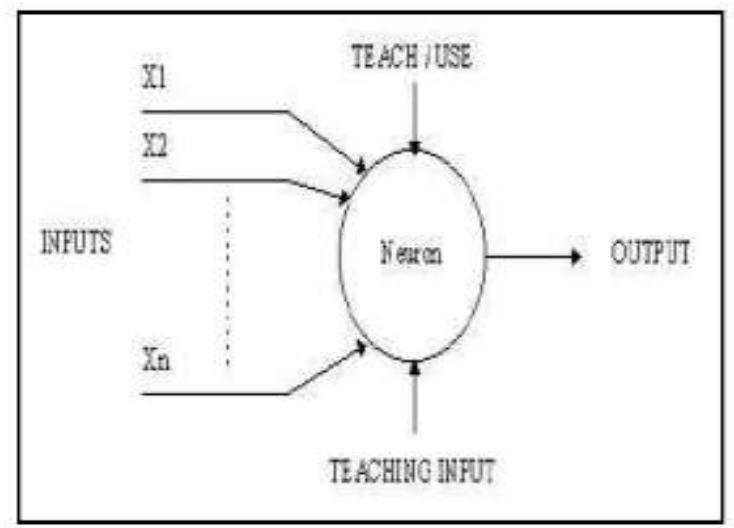

Fig. 1: Neural Network 
An Artificial Neural Network (ANN) is an information processing paradigm that is inspired by the way biological nervous systems, such as the brain, process information. The key element of this paradigm is the novel structure of the information processing system. It is composed of a large number of highly interconnected processing elements (neurones) working in unison to solve specific problems. ANNs, like people, learn by example. An ANN[5][6] is configured for a specific application, such as pattern recognition or data classification, through a learning process. Learning in biological systems involves adjustments to the synaptic connections that exist between the neurones. This is true of ANNs as well.

\section{LITERATURE SURVEY}

In[2] The author of this paperaims to identify classification criteria for good customers and bad customers in Iranian banks. This study can classified in applied studies group and the research strategy is descriptive. Artificial neural network technique is used for financial facilities applicants' credit risk measurement and the calculations have been done by using SPSS and MATLAB software. Number of samples was 497 and 18 variables were used to identify good customers from bad customers. The results showed that, individual loan frequency and amount of loan had most important effect and also status of customer's bank account, history of customer relationship with bank and received services had least important effect in identifying classification criteria of good and bad customers. The major contribution of this paper is specifying the most important determinants for rating of customers in Iran's banking sector.

In[3] The literature on dynamic pricing and learning has grown fast in recent years, with contributions from different scientific communities: operations research and management science (OR/MS), marketing, computer science, and economics / econometrics. This survey aims at bringing together the literature from these different fields, and at highlighting some of the older (and sometimes forgotten) literature where many important results and ideas already can be found.

In[4] A brief review of the literature to determine the finished goods inventory reveals that it is promising to use ANN. However, no particular research has been proposed to optimize finished goods inventory level considering the issues of products demand, setup cost, holding and material cost as input. To fill this gap, new tools or methods are important which can accommodate the fluctuating nature of the identified variables. By realizing the importance and the research gap, this paper deals with developing an ANN model which can be used to optimize finished goods inventory in a fuzzyenvironment. The input parameters of the ANN model are products demand, setup cost, holding cost, and material cost.

\section{PROPOSED METHODOLOGY}

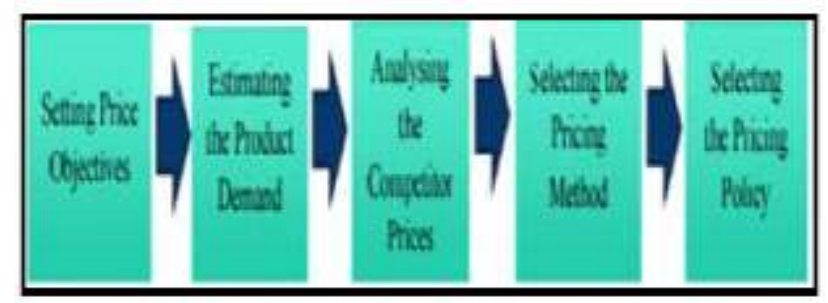

Fig 2: Working of proposed method

1. Setting Price ObjectivesRefers to set the goals of the pricing policy. An organisation can have multiple pricing objectives. Some of the price objectives are discussed as follows:

- Survival: Involves the formulation of a short-term price objective to face the fierce competition. The price of a product is reduced to increase sales volume.

- Quality of a product: Affects the price of products. An organisation incurs high cost in research and development cost in the price of the product.

2. Estimating the Product Demand Helps in knowing the factors that affect the demand of a product. Some of the important factors can be the prices of products, environmental factors, and income and expectations of customers.

3. Analysing the Competitor Prices Influences the decisions of setting the prices of products. The pricing strategies of competitors affect the demand of the product and lead to a loss of market share.

4. Selecting the Pricing Method Involves the selection of a technique for setting the price. There are various types of pricing methods used by organisations.

5. Selecting the Pricing Policy Involves a strategy or practice used by an organisation to achieve its pricing objectives. 


\section{SYSTEM ARCHITECTURE}

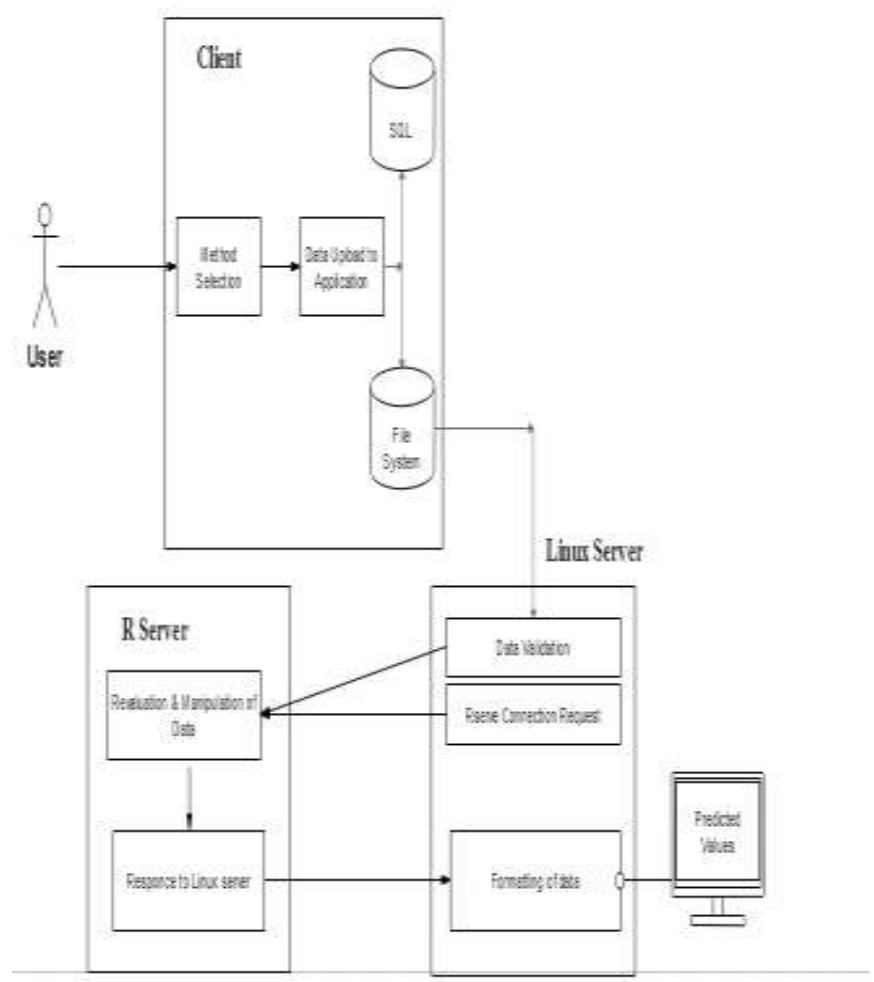

Fig. 3. System architecture

System architecture is the conceptual design that defines the structure and behaviour of a system. An architecture description is a formal description of a system, organized in a way that supports reasoning about the structural properties of the system. It defines the system components or building blocks and provides a plan from which products can be procured, and systems developed, that will work together to implement the overall system.

The System architecture is shown below.

The modules are showed in diagram, they are

User: Users are the one who uses the service provided via devices.

Client: Client is the device that connected to internet by various means like Wi-Fi or Lan, Here in this client a dataset is uploaded one is saved to the database and other the server local file system

Linux Server: Linux server is the place where the application is been hosted, there will be a validation of data that is been uploaded by the client, once the validation is done there will be an internal server call to Rserve. If the validation is failed then there will be error that will be displayed.

R Server: $\mathrm{R}$ server is the main part where all the manipulation and process takes place, once the evaluation is done a response will be sent to the Linux server.

\section{IMPLEMENTATION}

In present days the customers' buying decision is not only determined by the product price. Along with the product price, customers purchase decision is also triggered by other attributes such as product quality, delivery time, after sale service, sellers' reputation etc. The preferable purchase attributes of product may vary from buyers to buyers. To demonstrate this, let us assume that the price for a product, $\mathrm{P}$, based on different attributes is offered by three different sellers according to Table 1 . If a buyer BA is concerned with the quality of products, then he/she may prefer to buy the product, $\mathrm{P}$, from the seller SB who offers the best price amongst the three sellers when price is set based on product quality. Similarly, a buyer BB would choose seller SA when he/she wish to enjoy after sale service.

Once the sellers set an initial price of the product, our model adjusts the price of the product automatically with the help of neural network in order to increase the revenue earned. In setting the initial price of a product, we assume that sellers use their prior knowledge about the prices of the product offered by other competing sellers. No other prior knowledge is used in the evaluation. In the following chapter we simulate an ecommerce market place with three different sellers. The sellers employ three distinct pricing techniques: our model, simple pricing algorithm and derivative-following (DF). 
Vol. 6, Issue 4, April 2017

Table. 1: Price offered by different sellers for a product, $P$, based on different attributes

\begin{tabular}{|c|c|c|c|c|c|}
\hline Seller & $\begin{array}{l}\text { Product } \\
\text { Prict }\end{array}$ & $\begin{array}{l}\text { Product } \\
\text { Quality }\end{array}$ & $\begin{array}{l}\text { Deliner } \\
\text { Time }\end{array}$ & $\begin{array}{l}\text { After Sale } \\
\text { Strike }\end{array}$ & $\begin{array}{l}\text { Seller's } \\
\text { Reputation }\end{array}$ \\
\hline$S_{A}$ & 10.50 & 10.75 & 12.25 & 11.52 & 11.98 \\
\hline$S_{B}$ & 1150 & 10.65 & 12.85 & 11.54 & 11.62 \\
\hline$S_{C}$ & 10.5 & 10.95 & 12.50 & 11.61 & 11.25 \\
\hline
\end{tabular}

A seller, by taking five attributes of our model into consideration, could employ a simple pricing algorithm to determine a competitive price of products. A simple pricing algorithm may take at least the production cost of a product as initial selling price of the product. If a buyer prefers to enjoy any additional attributes such as after sale service, then the algorithmmay wish to add some additional price for each supplementary attributes. Finally, the algorithm would provide a selling price of the product. Since in online economy prices of products do not remain static, a seller has to frequently update his/her offered price of the products. While updating the prices, there can arrive two different scenarios for a seller who employs the simple pricing algorithm. First, the algorithm, while updating the price by adding extra amounts for additional attributes, does not use any information on how other competing sellers in the market set their selling price. Since the algorithm has no knowledge about market parameters, it uses some random extra prices for additional attributes. Hence, the price can be too low or too high which may lead to inadequate revenuefor a seller. In other words, sellers employing a simple pricing algorithm run a risk of earning less revenue. In the second scenario let us assume that a seller who employed the simple algorithm, do some manual search on the prices offered by other vendors. The algorithm uses information obtained from the seller's search to determine a selling price for products. However, the manual search could be time consuming. It might take from hours to days or even longer to gather information by manual search. Since prices change within very short span of time in online market, the information acquired by manual search during relatively large span of time might become outdated. Consequently, the algorithm would be using obsolete information which may lead to inappropriate output. In contrary, our model outputs a competitive selling price of products by providing importance to the five attributes based on historical data, which implies it does not rely on any manual search. In addition, our technique, while determining competitive selling price, considers the sellers make use of their prior knowledge of the prices set by other competing sellers in providing initial input to the model. This indicates that our model keep an eye on the competitiveprice set by other sellers in competing market and utilizes fresh information of price. In other words, our technique performs better than manual search in terms of time and non-obsolete information.

\section{RESULTS}

The below figure shows the output of proposed model. Sample input dataset is provided and the predicted output values are also shown.

\section{Sample Input Dataset Provided:}

Table1: Input dataset

\begin{tabular}{|c|c|c|c|c|c|c|}
\hline \multicolumn{7}{|c|}{ 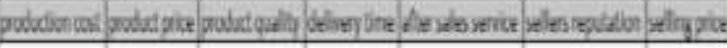 } \\
\hline Mise: & mas: & 1109 & 151 & tense & 楼275 & 266 \\
\hline $\mathrm{x}, \mathrm{ken}$ & 7H:5 & 394 & $324 \pi$ & 골다 & 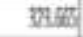 & 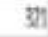 \\
\hline $118 \pi x^{2}$ & 114:5 & 194. & $12 \times$ & 145 & 1395 & B \\
\hline 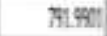 & thas & 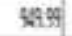 & math & 9745 & 㘹10 & fir \\
\hline 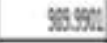 & 㬎: & 1996 & Isass: & 11695 & w:Les: & 11:. \\
\hline 1780: & 1728 & nogs] & 2085: & wse & 2728 & 20 \\
\hline 118750: & 100.2 & $120 \mathrm{~ms}$ & 1254 & $152 \%$ & 10225 & $12:$ \\
\hline 3655: & 문.5 & 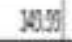 & 10.37 & 385 & BLSEE & 38 \\
\hline $185:$ & $19 \%$ & 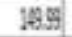 & $13 \%$ & 1354 & 57305 & 15 \\
\hline 15X3: & we: & 124] & 1124 & ne & 13 & 24: \\
\hline
\end{tabular}


Output for sample dataset provided: Table 2: output

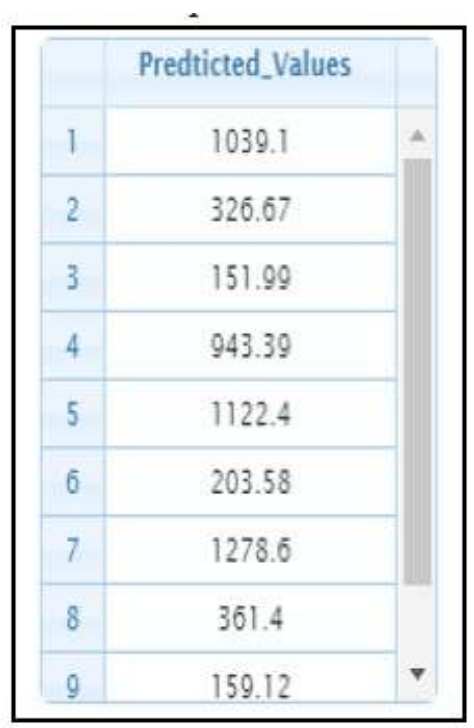

\section{CONCLUSION}

Dynamic pricing with incomplete demand information is a topic that has received considerable research attention in recent years. Different scientific communities have studied characteristics of pricing policies, usually with different aims in mind: the operations research / management science literature typically focuses on finding an optimal pricing policy from the perspective of a seller, and on proving optimality properties in tractable models; the economics literature is generally more concerned with explaining price behaviour and price formation observed in markets; and the computer science literature is typically not afraid to consider complicated demand models that are not tractable for mathematical analysis, but that can be handled using appropriate machine learning techniques. In spite of these different aims, there is much in overlap in the studied demand models, proposed pricing policies, and the techniques deployed to analyse the behaviour of these policies. With this survey we aim to provide a comprehensive overview of these studies, and facilitate further research on this broad and lively research topic.

\section{FUTURE ENHANCEMENTS}

Future enhancement of this project is, the time complexity can be reduced and also the price of a particular product will be detected by using natural language processing algorithm. The major enhancement is by increasing the accuracy of the optimized price and also the forecast of the optimized price by predicting the time till which the price can sustain in the market.

\section{REFERENCES}

[1] J. Kephart and J. Hanson, A. Greenwald. Dynamic Pricing by Software Agents, Computer Networks,32,731-752 (2000)

[2] AHP-Neural Network Based Player Price Estimation in IPL Pabitra Kr. Dey1, Abhijit Banerjee2, DipendraNath Ghosh3, Abhoy Chand Mondal4

[3] A Dynamic Pricing Method in E-CommerceBased on PSO-trained Neural NetworkLiang Peng and HaiyunLiuSchool of economics,Huazhong University of Science and Technology

[4] APPLICATION OF INTELLIGENT METHODS IN COMMERCIAL WEBSITE MARKETING STRATEGIES DEVELOPMENT AlgirdasNoreika Department of Practical Informatics, Kaunas University of Technology Studentųst.50, LT - 51368, Kaunas, Lithuania

[5] An artificial neural network model for optimization of finished goods inventory Sanjoy K. Paula* and AbdullahilAzeema

[6] Ajith Abraham, “Artificial Neural Networks” http://www.softcomputing.net/ann_chapter.pdf 